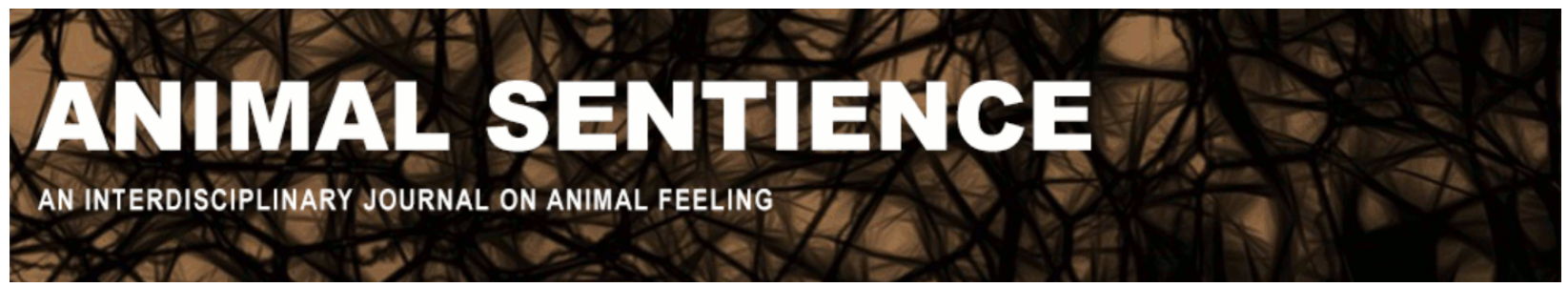

Delon, Nicolas; Cook, Peter; Bauer, Gordon; and Harley, Heidi (2020) Consider the agent in the arthropod. Animal Sentience 29(32)

DOI: $10.51291 / 2377-7478.1623$

Date of submission: $2020-07-24$

Date of acceptance: 2020-07-29

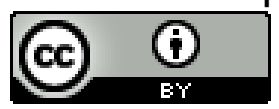

This article has appeared in the journal Animal

Sentience, a peer-reviewed journal on animal

cognition and feeling. It has been made open access,

free for all, by WellBeing International and deposited

in the WBI Studies Repository. For more information,

please contact

wbisr-info@wellbeingintl.org.

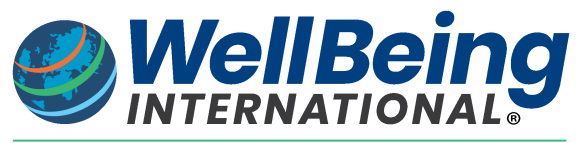

SOLUTIONS FOR PEOPLE, ANIMALS AND ENVIRONMENT 


\title{
Consider the agent in the arthropod
}

Commentary on Mikhalevich \& Powell on Invertebrate Minds

\author{
Nicolas Delon \\ Philosophy and Environmental Studies, New College of Florida \\ Peter F. Cook \\ Psychology, Emeritus, New College of Florida \\ Gordon B. Bauer \\ Psychology, New College of Florida \\ Heidi E. Harley \\ Psychology and Environmental Studies, New College of Florida
}

\begin{abstract}
Whether or not arthropods are sentient, they can have moral standing. Appeals to sentience are not necessary and retard progress in human treatment of other species, including invertebrates. Other increasingly well-documented aspects of invertebrate minds are pertinent to their welfare. Even if arthropods are not sentient, they can be agents whose goals-and therefore interests-can be frustrated. This kind of agency is sufficient for moral status and requires that we consider their welfare.
\end{abstract}

Nicolas Delon teaches philosophy and environmental studies. His research focuses on the moral status of animals. He's also interested in agency, mind, food, and Nietzsche. Website

Peter F. Cook is a comparative psychologist and neuroscientist focused on brain connectivity and ecologically valid study design. He studies memory, rhythm, affect, and behavioral flexibility, mostly in carnivores. Website

Gordon Bauer taught at New College of Florida for 26 years. He studies animal senses, cognition, and behavior in species including manatees, bottlenose dolphins, humpback whales, and sea turtles. Website

Heidi Harley teaches cognitive psychology and comparative cognition. Her research focuses on cognitive processes in dolphins. Website
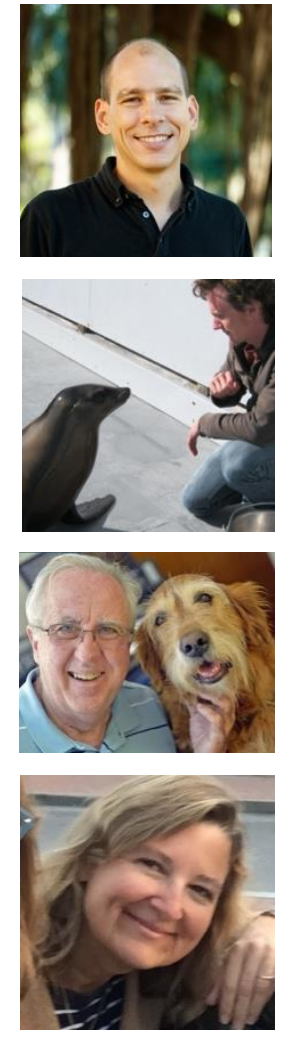
Arthropods can have moral standing irrespective of whether they are sentient. Mikhalevich \& Powell (2020) (M\&P) make an impressive case for taking the welfare of invertebrates seriously in ethical decision-making. They rebut arguments that suggest invertebrates, especially arthropods, do not count when it comes to welfare - that it is not possible to harm them because nothing really matters to them. The presupposition is that for our treatment of invertebrates to matter, things must matter to them. We agree that invertebrates matter, and that their welfare is morally significant. Where we depart from M\&P, and from most of the published commentaries, is in what we think makes this true. Appeals to sentience are not necessary and impede progress in our treatment of other species, including invertebrates. We turn instead to other welldocumented aspects of invertebrate minds that pertain to their welfare: Even if arthropods are not sentient, they can be agents whose goals - and therefore interests - can be frustrated. This kind of agency is sufficient for moral status and makes invertebrate welfare morally significant.

Sentience, whatever its functional value, is not logically necessary for the bulk of animal behavior (nonhuman and human). Well established among myriad such examples are the following: Blindsight is a condition in which cortically blind subjects have no awareness of visual stimuli yet they are able to discriminate features such as movement, location, orientation, and color (Weiskrantz, 1995). Basic learning processes -- long the dominant interest in psychology, and the root of flexible behavior -- occur outside of awareness in humans, with no apparent role for sentience in autonomous systems (Michie et al. 1994). Beyond perception and learning, even complex decision making in humans is facilitated by processes outside awareness (Dijksterhuis, 2004). Hence, sentience need not drive other species' behavior.

To survive and flourish most animals nevertheless have motivational systems that drive them toward goals flexibly, in ways that differ from straightforward physical phenomena like an air bubble's rise toward the surface of water. The air bubble's behavior is dictated by the physical forces alone, whereas many invertebrate species, for example, honeybees (Wei et al. 2002), can make decisions among alternatives to reach their goals and can learn based on the outcomes. (Carruthers, 2018a, discusses curiosity in insects.) It is such flexible goal-driven behavior that William James (1890) considered criterial for having a psychology (or a mind).

In humans, the motivational systems that drive our learning and decision-making include representations of bodily states associated with emotion and assessments of the probability of different bodily states given different possible outcomes (Bechara and Damasio 2005). Whereas much of this assessment seems to take place with conscious access in humans, there is no reason to suppose that these integrative representational systems for driving flexible action require sentience to function (Cook 2017).

Much more evidence is needed about how arthropods and other invertebrates evaluate potential behavioral outcomes but there is already clear evidence that some insect nervous systems are wired to allow integrative representation of experience and to contribute to future behavior. Such systems might also ground interests when the system is capable of valenced and internally referenced representations of action-perception schemas (Faber et al. 1999; Perry and Barron 2013) -- representations whose contents include a positive or negative relation with the environment and the system itself. (Carruthers 2018b discusses valence as a nonconceptual representation of value.) For example, an ant may recognize a stimulus that was previously associated with bodily harm and thus act to avoid it. There is perhaps a minimal threshold of 
integration and coordination of representations along with flexibility of representation-based behavior, but much of the evidence reviewed by M\&P indicates that many arthropods pass this threshold: Their nervous systems allow them to represent their own bodies and bodily states, link these representations with other representations (e.g., of the environment, either positive or negative), and use them flexibly in decision-making (i.e., their responses).

Although Carruthers (2007) argues that invertebrates exhibit the features of agency, and thus have interests that can be thwarted, he denies that such features give invertebrates moral claims against us (Fischer 2016). We disagree: agency can be a criterion for moral standing. It is very common among theories of moral standing to consider sentience as the necessary and sufficient criterion, with agency only an enhancing factor. This is to assume that agency requires sentience. However, agency could also be the necessary and sufficient criterion, with sentience only an enhancing factor. If invertebrates can be agents, our inability to determine whether they are sentient should not be an obstacle to considering their welfare. On this view, the implications of rejecting appeals to sentience in arthropods could be no less compassionate than arguments relying on the claim that they are sentient. All animals, including humans, have motivations operating outside of consciousness to seek out or avoid certain beneficial or harmful stimuli. What matters to agents can matter to them as agents, even if it can also matter through sentience. Sentience is not necessary for agency, as shown by the examples above. Flexible representations and behavior characteristic of agents can occur without sentience and often preempt it even in sentient organisms.

Taking agency-a capacity for flexible action based on representations of potential goal states-as an independent source of moral standing is coherent and has a long history in moral philosophy. Kagan (2019) recently made such a case, taking the capacity for basic intentional action (motivated by internal representations) to be sufficient for agency. Some invertebrates would qualify according to his account. Other recent accounts of the moral status of animals have argued for the significance of animal agency, even when they claim that sentience and agency stand or fall together (Healey and Pepper 2020; Jamieson 2018; Purves and Delon 2018; Sebo 2017; Wilcox 2020). If, as we argue, agency does not require sentience, then insentient agents can have moral standing.

Organisms that can represent their goals and act flexibly to achieve them can be seen as agents. The central insight of theories of well-being according to which 'desire-satisfaction' (i.e. goal-attainment or -thwarting) contributes to (or detracts from) well-being is that reaching the goal matters independently of the feeling of satisfaction. Such theories are not confused. Even if some other mental state were required for attainment or thwarting to count (e.g., the motivational system registers it and revises action-plans by representing the state of affairs as 'bad', 'undesired' or 'to be avoided'), we would still not have to appeal to sentience. Valenced states can motivate intentional action without feeling like anything.

Arthropods represent the world but also what they are doing. Ants may not know why, but we can still answer why ants do what they do; not just in the causal sense but by appealing 
to reasons. ${ }^{1}$ Hence, if insects are indeed agents, meaningful claims can be made about invertebrate welfare even if it is unknown whether they are sentient, even if it is known that they cannot be sentient and even if, as Carruthers (2019) puts it, "there is no fact of the matter" as to whether nonhuman animals are sentient. Future philosophical and empirical work could explore what sorts of interests different species have and what they entail for our treatment of insects and other invertebrates in agriculture, captivity, research, 'pest' control, and conservation.

\section{References}

Bechara, A., \& Damasio, A. R. (2005) The somatic marker hypothesis: A neural theory of economic decision. Games and economic behavior 52(2): 336-372

Carruthers, P. (2007) Invertebrate minds: A challenge for ethical theory. The Journal of Ethics 11(3): 275-297

Carruthers, P. (2018a) Basic questions, Mind \& Language 33: 130-147

Carruthers, P. (2018b) Valence and value. Philosophy and Phenomenological Research 97(3): 658680

Carruthers, P. (2019) Human and animal minds: The consciousness questions laid to rest. Oxford University Press

Cook, P. F. (2017) Studying dog emotion beyond expression and without concern for feeling. Animal Sentience 2(14)

Dijksterhuis, A. (2004) Think different: the merits of unconscious thought in preference development and decision making. Journal of personality and social psychology 87(5): 586

Faber, T., Joerges, J., \& Menzel, R. (1999) Associative learning modifies neural representations of odors in the insect brain. Nature neuroscience 2(1): 74-78

Fischer, B. (2016) What if Klein \& Barron are right about insect sentience? Animal Sentience 9(8)

Harland, D.P., Jackson, R.R. (2000) Eight-legged cats and how they see: A review of recent research on jumping spiders (Araneae: Salticidae). Cimbebasia 16: 231-240

Healey, R., Pepper, A. Interspecies justice: agency, self-determination, and assent. Philosophical Studies.

James, W. (1890) [2007] The principles of psychology (Vol. 1). Cosimo, Inc.

Jamieson, D. (2018) Animal agency. The Harvard Review of Philosophy 25: 111-126

Kagan, S. (2019) How to count animals, more or less. Oxford University Press

Michie, D., Spiegelhalter, D. J., \& Taylor, C. C. (1994) Machine learning. Neural and Statistical Classification. Overseas Press

Mikhalevich, Irina \&Powell, Russell (2020) Minds without spines: Evolutionarily inclusive animal ethics. Animal Sentience 29(1)

\footnotetext{
${ }^{1}$ Philosophers have paid little attention to the possibility of insect agency. On whether ants are capable of intentional action, see Setiya (2017) and Singh (2017) at The Daily Ant blog. On the 'jumping' spider, Portia, see Steward (2012, 108-109) and Proust (2013, 131-135). Cf. Harland and Jackson (2000) for empirical discussion.
} 
Perry, C. J., \& Barron, A. B. (2013) Neural mechanisms of reward in insects. Annual review of entomology 58: 543-562

Proust, J. (2013) The philosophy of metacognition: mental agency and self-awareness. Oxford University Press

Purves, D., Delon, N. (2018) Meaning in the lives of humans and other animals. Philosophical Studies 175(2): 317-338

Sebo, J. (2017) Agency and moral status. Journal of Moral Philosophy 14(1): 1-22

Setiya, K. (2017) Ant-I-intellectualism. The Daily Ant, 29 September 2017

Singh, K. (2017) Do ants do things for reasons? The Daily Ant, 31 March 2017

Steward, H. (2012) A metaphysics for freedom. Oxford University Press

Wei, C., Rafalko, S. \& Dyer, .F. (2002) Deciding to learn: modulation of learning flights in honeybees, Apis mellifera. Journal of Comparative Physiology A, 188: 725-737

Weizkrantz, L. (1995) Blindsight-not an island unto itself. Current Directions in Psychological Science 4: 146-150

Wilcox, M. G. (2020) Animals and the agency account of moral status. Philosophical Studies 177(7): 1879-1899 